\title{
Choice of fluids in critically ill patients
}

\author{
Claude Martin ${ }^{1}$, Andrea Cortegiani $^{2^{*}}$ (1), Cesare Gregoretti ${ }^{2}$, Ignacio Martin-Loeches ${ }^{3,4}$, Carole $_{\text {Ichai }}{ }^{5}$, Marc Leone $^{6}$, \\ Gernot Marx ${ }^{7}$ and Sharon Einav ${ }^{8,9}$
}

\begin{abstract}
Background: Fluids are by far the most commonly administered intravenous treatment in patient care. During critical illness, fluids are widely administered to maintain or increase cardiac output, thereby relieving overt tissue hypoperfusion and hypoxia.

Main text: Until recently, because of their excellent safety profile, fluids were not considered "medications". However, it is now understood that intravenous fluid should be viewed as drugs. They affect the cardiovascular, renal, gastrointestinal and immune systems. Fluid administration should therefore always be accompanied by careful consideration of the risk/benefit ratio, not only of the additional volume being administered but also of the effect of its composition on the physiology of the patient. Apart from the need to constantly assess fluid responsiveness, it is also important to periodically reconsider the type of fluid being administered and the evidence regarding the relationship between specific disease states and different fluid solutions.

Conclusions: The current review presents the state of the art regarding fluid solutions and presents the existing evidence on routine fluid management of critically ill patients in specific clinical settings (sepsis, Adult Respiratory Distress Syndrome, major abdominal surgery, acute kidney injury and trauma).
\end{abstract}

Keywords: Fluids, Resuscitation, Critically ill, Crystalloid, Colloid, Intensive care unit

\section{Background}

Fluids are probably the most commonly administered intravenous treatment in inpatient care. Because of their excellent safety profile, until recently fluid solutions were not considered "medications" [1]. Little to no thought was therefore invested in the choice of fluids to be administered in specific clinical scenarios. However, recent evidence on long-term effects has altered our view on the different types of fluids available for fluid resuscitation. Intravenous fluids should be seen as drugs affecting the cardiovascular, renal, gastrointestinal and immune systems and should therefore not be administered "blindly".

Emphasis on the importance of volume above all the other characteristics of the fluids administered was nurtured by early guidelines that focused on administering specific fluid volumes to hemodynamically unstable patients (i.e. the surviving sepsis campaign) [2, 3]. It is true that fluid administration is an important component of treatment of

\footnotetext{
* Correspondence: andrea.cortegiani@unipa.it

${ }^{2}$ Department of Surgical, Oncological and Oral Science (Di.Chir.On.S.). Section of Anesthesia, Analgesia, Intensive Care and Emergency. Policlinico Paolo Giaccone. University of Palermo, Via del vespro 129, 90127 Palermo, Italy Full list of author information is available at the end of the article
}

overt tissue hypoperfusion and hypoxia. Fluids may expand the intra-vascular compartment, thereby improving cardiac output $(\mathrm{CO})$ and end-organ perfusion $[3,4]$. However, the most common error with regards to fluid administration is the belief that resuscitation hinges on transfusion of a specific volume of fluids $[3,5]$.

Disease processes are dynamic and their response to fluid may change over time. Specific disease states may also require different fluid therapy. Evidence from perioperative settings has associated both hypo- and hypervolemia with several unfavorable outcomes, including acute kidney injury (AKI), respiratory complications, increased lengths of stays, admission costs and 30-day-mortality rates $[6,7]$. Later iterations of the guidelines have therefore clarified that the aim of fluid resuscitation is restoration of end-organ perfusion and correction of physiological imbalance. Follow-up during fluid administration should therefore include surrogate markers of organ perfusion (e.g. mean arterial pressure, central venous oxygen saturation, lactate, $\mathrm{CO}$ ), markers of circulation, blood electrolyte and acid-base composition and indicators of renal function $[3,8]$. No fluid is ideal for all disease conditions at all times. This review presents the 
current state of knowledge regarding the types of fluids to be administered with an emphasis on several disease states.

\section{Methods}

The concept of this review was put forward during Euroanesthesia 2015, in the Intensive Care Subcommittee meeting which is open to all attendees. The subcommittee meeting is typically attended by intensive care physicians who are also anaesthesiologists with an interest in promoting research in their field. Following group discussion of several options proposed, the attending subcommittee members selected this topic as worthy of address. The authors to be approached were determined based on their previous contribution to the international literature on specific related topics and their writing experience. All those approached agreed to contribute.

For the first section of this paper ("Types of fluid") a non-systematic search of Pubmed was performed. For the second part ("Fluid administration in specific disease conditions") the services of a professional librarian were employed and a systematic search of the literature was performed. The systematic search was conducted in both Pubmed ${ }^{\mathrm{m}}$ and Embase ${ }^{\mathrm{Tu}}$ databases and included all publications until June 30th 2018. The Cochrane database is embedded in full in both of these databases therefore a separate search was not conducted for the Cochrane database. The key words used were "fluid administration" OR "fluid therapy" OR "fluid resuscitation" AND "ICU" OR "critically ill" OR trauma OR sepsis OR "major abdominal surgery" OR "respiratory distress syndrome" OR "acute kidney injury". The filters applied included human subjects, adults and publication in the English language. Only studies with original data (observational, retrospective or prospective), reviews, systematic reviews and meta-analyses were included. After exclusion of duplicate publications this search yielded 3364 potential papers of interest (see Additional file 1).

The titles of this list of articles were screened five times by the authors. Each searched for papers with content relevant to their specific clinical condition of interest. Screening for sepsis was conducted by CDM and IML, for major abdominal surgery by SE, for acute respiratory distress syndrome (ARDS) by CG and AC, for trauma by ML, and for acute kidney injury by $\mathrm{CI}$. Based on this initial screening 669 papers were selected for review of the abstract. For each section two of the authors then reviewed the abstracts and selected the articles for full download. Overall 147 articles were reviewed in full text (See Fig. 1 for the full publication inclusion/exclusion process). The references of these articles were then manually screened for additional potentially relevant papers. The two main selection criteria to determine final inclusion were relevance to the topic at hand and the quality of the paper based on expert opinion. For specific issues, additional seminal studies were used at the discretion of the authors.

\section{Types of fluids}

The following section discusses the characteristics of most existing fluid solutions. The chemical composition of many of the solutions currently on the market is presented in Table 1.

\section{Crystalloids}

Given the current controversy surrounding administration of colloids, crystalloids have prudently been selected as the first choice for fluid resuscitation. Unbalanced crystalloid solutions (i.e. saline solutions) typically contain high concentrations of sodium-chloride and have a $\mathrm{pH}$ that is lower than 6.0. In this sense, the term "normal" saline is a misnomer. The characteristics of saline solutions depend on their salt concentration $(0.9,0.45$, $3 \%$ etc.). Balanced crystalloid solutions (e.g. Ringer's

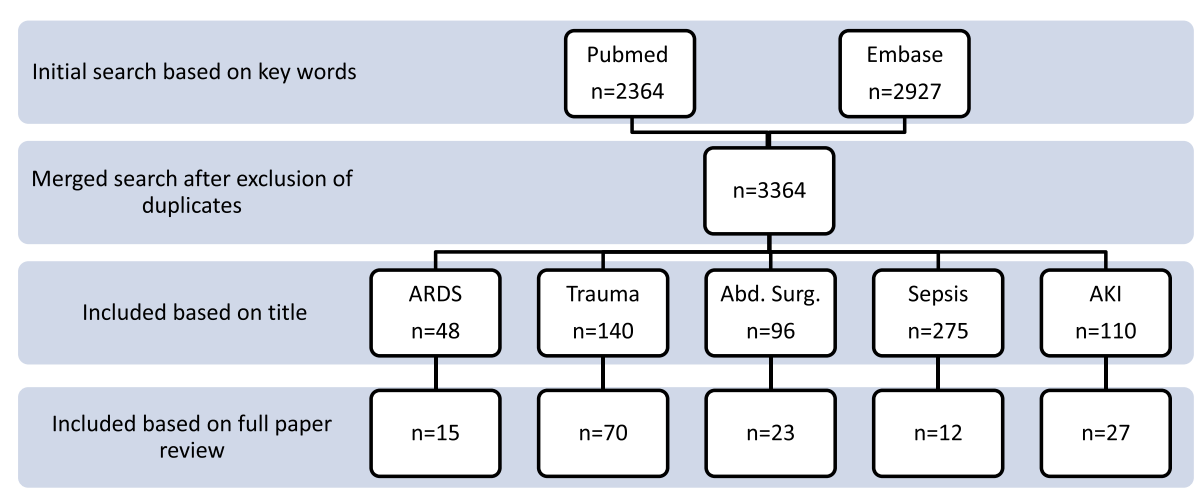

Fig. 1 Flow diagram of the systematic search of the literature 
Table 1 The chemical composition of commonly used intravenous fluid solutions

\begin{tabular}{|c|c|c|c|c|c|c|}
\hline Solutions & $\mathrm{Na}^{+}(\mathrm{meq} / \mathrm{L})$ & $\mathrm{K}^{+}(\mathrm{meq} / \mathrm{L})$ & $\mathrm{Cl}^{-}(\mathrm{meq} / \mathrm{L})$ & Other anions (meq/L) & $\begin{array}{l}\text { Osmolarity } \\
\text { (mosm/L) }\end{array}$ & $\begin{array}{l}\text { In vivo SID } \\
(\mathrm{meq} / \mathrm{L})\end{array}$ \\
\hline \multicolumn{7}{|l|}{ Crystalloids } \\
\hline \multicolumn{7}{|l|}{ Unbalanced } \\
\hline $\mathrm{NaCl} 0.9 \%$ & 154 & 0 & 154 & - & 308 & - \\
\hline $\mathrm{NaCl} 3 \%$ & 510 & 0 & 510 & - & 1026 & - \\
\hline $\mathrm{NaCl} 7.5 \%$ & 1275 & 0 & 1275 & - & 2395 & - \\
\hline \multicolumn{7}{|l|}{ Balanced } \\
\hline Lactate Ringer & 130 & 4 & 108 & Lactate (27.6) & 277 & 27 \\
\hline Acetate Ringer & 132 & 4 & 110 & Acetate (29) & 277 & 27 \\
\hline \multirow[t]{2}{*}{ Acetate Gluconate (Plasmalyte ${ }^{\oplus}$ ) } & 140 & 5 & 98 & Acetate (27) & 294 & 50 \\
\hline & & & & Gluconate (23) & & \\
\hline \multirow[t]{2}{*}{ Acetate Malate (Isofundin ${ }^{\oplus}$ ) } & 145 & 4 & 127 & Acetate (24) & 304 & 27 \\
\hline & & & & Malate (5) & & \\
\hline \multicolumn{7}{|l|}{ Colloids } \\
\hline \multicolumn{7}{|l|}{ Unbalanced } \\
\hline Hydroxyethylstarch (Voluven ${ }^{\oplus}$ ) & 154 & 0 & 154 & - & 308 & - \\
\hline Albumin & 154 & 0 & 154 & - & 308 & - \\
\hline \multicolumn{7}{|l|}{ Balanced } \\
\hline \multirow[t]{2}{*}{ Hydroxyethylstarch (Tetraspan®) } & 140 & 4 & 118 & Acetate (24) & 297 & 29 \\
\hline & & & & Malate (5) & & \\
\hline Hydroxyethylstarch (Hextend ${ }^{\oplus}$ ) & 143 & 3 & 124 & - & 307 & 28 \\
\hline Gelatins 4\% (Plasmion $\left.{ }^{\oplus}\right)$ & 154 & 0 & 120 & - & 307 & 32 \\
\hline Gelatins 3\% (Gelofusin ${ }^{\oplus}$ ) & 150 & 0 & 100 & - & 284 & 56 \\
\hline
\end{tabular}

${ }^{\mathrm{a}}$ Strong lon Difference

lactate, Plasma-Lyte, Isofundine) are buffered by anions other than chloride. The chloride concentrations of balanced solutions therefore more closely approximate plasma but their osmolality is lower and they contain alternative anions in non-physiological concentrations. Lactate-buffered fluids are the least costly in this fluid category.

Crystalloids, chloride concentrations and renal failure The concentration of chloride in $0.9 \%$ saline solution exceeds that of plasma $(154 \mathrm{mEq} / \mathrm{L})$. Experimental studies have shown that high renal tubular chloride concentrations induce renal afferent vasoconstriction with a resultant decrease in renal blood flow and GFR $[9,10]$. No similar effect has been observed with relation to elevated sodium concentrations [11]. Moreover, canine models demonstrate that when accompanied by hypovolemia, the reduction in renal blood flow doubles compared to euvolemia [11]. In humans, administration of isotonic saline has been shown to cause hyperchloremic acidosis in both non critically ill [12] and critically ill patients [13, 14]. In healthy human volunteers, administration of intravenous
$0.9 \%$ saline has also been shown to decrease renal blood flow velocity and renal cortical tissue perfusion when compared to a balanced solution (e.g. plasma-lyte 148) [15].

Summary statements:

- Animal and human studies demonstrate that high renal tubular chloride concentrations induce renal afferent vasoconstriction with a resultant decrease in renal blood flow.

- Given that the availability and cost of saline and balanced crystalloids are not significantly different, saline should probably no longer be used for intravascular volume expansion.

\section{Colloids}

Colloids contain macromolecules such as hydroxyethylstarch (HES), gelatin, dextran, or albumin. In the past colloids were thought to be distributed primarily in the intravascular space and were therefore considered 3-4 times more effective than crystalloids for restoring intravascular volume. Clinical evidence supports the assumption of higher intravascular retention of colloids, albeit not to such extent. Administration of $1400-1800 \mathrm{ml}$ of 
gelatin, albumin, and HES increases cardiac index by $25-44 \%$ in surgical patients while administration of the same amount of saline $(1800 \mathrm{ml})$ does not affect cardiac index [16]. Clinical hemodynamic stabilization also seems to occur more rapidly and with smaller volumes of colloids compared to crystalloids [17]. Unfortunately, many studies yielding such evidence were not designed for this purpose, which limits the validity of their findings.

Today it is clear that the ratio of intravascular to administered volume of colloids is usually only 1:1.2 $[4,16-19]$, far less than previously believed. Large multicentre, randomised trials have shown ratios $<1: 2$ [16-19]. Furthermore, many trials noting decreased transfusion requirements with the use of colloids are being criticised for bias, as fluid therapy was often determined by the treating clinicians [17-19].

\section{Hetastarch (HES)}

Three large RCTs have associated administration of HES with AKI and the need for RRT in ICU patients, especially in those with sepsis [19]. Three randomized controlled studies comparing intraoperative administration of HES versus crystalloids yielded conflicting results; HES was responsible for an increased incidence of renal dysfunction in two studies [20,21] but no such effect was observed in the third [22].

The findings from meta-analyses suggest this finding may depend on the patient cohort. Three meta-analyses (two including general critically ill patients and one septic patients receiving fluids for resuscitation) confirmed the higher risk of AKI but reported conflicting results for mortality [23-25]. One further meta-analysis comparing HES to crystalloids in RCTs of patients without sepsis did not demonstrate any difference in the incidence of RRT or overall mortality. In this analysis, however, the total volume of fluids administered to patients receiving colloids was lower [26] raising questions regarding the parallel protective effect of administration of less fluids. Two meta-analyses performed in surgical patients showed that intraoperative HES administration did not increase either the incidence of AKI or mortality $[27,28]$.

Nonetheless in 2013, The European Medicines Agency decided that HES should not be used in critically ill patients in the EU and the US due to lack of supportive evidence and some safety concerns $[29,30]$. More recently, the Co-ordination group for Mutual recognition and Decentralised procedures - human (CMDh) of the European Medicines Agency (EMA) recommended suspension of marketing authorisations for HES (apart from controlled clinical trials), "because of the risk of kidney injury and death in certain patient populations" [29].

\section{Albumin}

Albumin is the only natural colloid used for intravascular volume replacement in humans. In the past, administration of albumin was thought to increase mortality. However, in 2013, a repeat Cochrane meta-analysis found no evidence of such adverse effect [31]. The multicentre Saline versus Albumin Fluid Evaluation (SAFE) study performed in 2004 was probably the decisive factor in this reappraisal. In the SAFE study, no difference was found between hypovolaemic patients treated with albumin $(n=3497)$ or saline $(n=3500)$ in mortality, length of ICU or hospital stay, or organ dysfunction [18]. The main criticisms of the SAFE study are that the presence of hypovolemia was not determined based on predetermined criteria and that the dose of fluid to be administered was not preset [18].

Three meta-analyses have studied whether human albumin affects mortality when administered for intravascular volume expansion to critically ill patients with sepsis [32-34]. These are discussed in greater detail in the section on sepsis (see below). Taken together, it is safe to state there is no good-quality evidence regarding the value of resuscitation of critically ill patients using albumin.

\section{Summary statements:}

- It remains unclear whether albumin confers either benefit or risk in terms of mortality and renal function.

- Given the cost of human albumin, it should generally not be considered the first choice for fluid replacement unless there is a specific indication for its use.

\section{Gelatin}

Gelatin is a synthetic colloid with a molecular weight of $\sim 35 \mathrm{kDa}$ and a relatively short plasma half-life (approximating 2-3 h). The recent debate on colloids has focused on the adverse effects of gelatin; namely increased renal injury, coagulopathy, anaphylaxis and mortality. Unfortunately few studies on gelatin have been sufficiently powered to reveal valid patient-centered outcomes [31, 35, 36]. Adequately powered controlled, randomised, double-blinded trials, such as GENIUS-trial which is currently recruiting (NCT02715466) are required.

Meta-analyses studying potential unwanted effects of gelatin (predominantly compared to crystalloids) have not shown increased renal injury, clinically relevant bleeding $[36,37]$ or even mortality $[31,35,36$, 38]. Bayer et al. used a sequential design to study three regimens of fluid administration to ICU patients [39]; HES plus crystalloids, Gelatin plus crystalloids, and crystalloids alone. The rate of renal replacement therapy was lower with crystalloids alone. Mortality, blood transfusion, and allergies did not differ [39, 40]. 
Despite the limitations of this study (i.e. confounding by inconsistent reporting and time-related treatment changes and differences in the volume of priming) these have been supported by Moeller et al. who report that German pharmacovigilance data do not indicate gelatin-induced renal injury [36]. Corroboration can also be found in a recent systematic review which reported a decreased risk of renal failure with gelatin when compared to any other intravenous fluid [41].

With regards to allergic reactions, one meta-analysis reported a significantly greater incidence of allergic responses with gelatin compared to crystalloids or albumin [36]. This result was dominated by a single study where urea-linked gelatine was used [42]. Urea-linked gelatine is far more allergenic than modified fluid gelatine (MFG), which exists in most such solutions to-date [43]. Allergic reactions to gelatin are typically mild and their incidence is much lower when MFG is used compared to older gelatin preparations [42, 43]. Existing evidence does not clearly demonstrate that gelatine has more adverse effects. However, the evidence on this topic remains clearly insufficient.

\section{Summary statements:}

- The evidence on gelatins remains clearly insufficient; few RCTs have been sufficiently powered to reveal valid patient-centered outcomes.

- Observational studies in large cohorts and metaanalyses comparing gelatine to crystalloids have mostly shown no different or even lower rates of renal injury, clinically relevant bleeding and death with gelatins.

- Allergic reactions are more common and more severe with urea-linked gelatin than with modified fluid gelatine but most studies comparing gelatins to crystalloids/albumin have failed to differentiate between the two.

\section{Dextrans}

The CMDh statement suggests that dextrans may be used as alternative fluid solutions in routine clinical practice [29]. This recommendation is somewhat questionable given the paucity of data regarding dextrans to-date.

Early trials studying EGDT either used no colloids at all [44] or were not explicit regarding the specific fluid solutions used [45-47]. The 6S [19], VISEP [17], CHEST [4], and CRYSTMAS [16] studies included no fluid solutions that contain dextrans. In the CRISTAL trial only five of the 1414 patients receiving colloids were treated with solutions containing dextrans [48]. A search of PubMed using the keywords "dextran/TI AND volume/ AB" (1998 to January 2018) yielded only 17 studies that describe the use of dextrans in humans and most of these were small studies focusing on dextran-based hyperoncotic therapy.

\section{Summary statement:}

- The CMDh stated that there are no legal constraints regarding the use of dextrans for intravascular fluid replacement at this time. Although this statement is probably true, there is also an alarming lack of evidence to support the recommendation to use these solutions in critically ill humans.

\section{In summary}

Balanced crystalloids are generally the solutions of choice for intravascular fluid resuscitation of hypovolaemic patients. The evidence against isotonic saline remains inconclusive but the possible risks associated with its use are not balanced by any advantage in therapeutic efficacy or cost at this time. Colloids are probably more effective than crystalloids, albeit not as effective as theoretically expected. However, no additional benefit has been conclusively proven for colloids over crystalloids. Therefore, if a decision has been made to administer colloids, it should always follow crystalloid administration. The solutions to consider after failed treatment with crystalloids should be either albumin or MFG. Regardless of the choice of colloids to be used, colloid administration should be considered rescue therapy and remain limited to profound, acute hypovolaemia.

\section{Fluid administration in specific disease conditions}

As noted above, there is accumulating evidence that specific disease states may require different fluid therapy. In the section below the data supporting this statement is presented for specific disease conditions often seen in the ICU (i.e. sepsis, major abdominal surgery, ARDS trauma and AKI). The guidelines published regarding fluid administration in these disease conditions are summarised in Table 2. Additional file 2 reports some of the most relevant articles retrieved by the systematic search.

\section{Sepsis}

Lactic acidosis is a major metabolic side effect of sepsis. As noted above, intravenous administration of $0.9 \%$ saline may cause iatrogenic hyperchloremic acidosis [12, 49]. Hyperchloremia has been associated with increase in mortality in both septic and non-septic patients [50]. However, most studies examining this issue were retrospective, which precludes derivation of a meaningful causative association between the two. Studies comparing solutions with high versus low-chloride concentrations have yielded conflicting results thus far. Reduced rates of mortality and AKI have been described with balanced solutions [12, 13, 15, 49, 51] therefore until more information from RCTs is available, balanced solutions remain preferred over $0.9 \%$ saline for the treatment of hemodynamically unstable septic patients. 
Table 2 Guidelines on fluid management and resuscitation

\begin{tabular}{|c|c|c|c|}
\hline Guideline title & Authors, year & Recommendations & Grade \\
\hline \multirow{6}{*}{$\begin{array}{l}\text { Surviving Sepsis Campaign: } \\
\text { international guidelines for } \\
\text { management of sepsis and } \\
\text { septic shock: } 2016\end{array}$} & \multirow[t]{6}{*}{ Rhodes A. et al. 2017 [2] } & $\begin{array}{l}\text { We recommend that a fluid challenge technique be } \\
\text { applied where fluid administration is continued as } \\
\text { long as hemodynamic factors continue to improve }\end{array}$ & $\begin{array}{l}\text { Best practice } \\
\text { statement }\end{array}$ \\
\hline & & $\begin{array}{l}\text { We recommend crystalloids as the fluid of choice } \\
\text { for initial resuscitation and subsequent intravascular } \\
\text { volume replacement in patients with sepsis and } \\
\text { septic shock }\end{array}$ & $1 \mathrm{~B}$ \\
\hline & & $\begin{array}{l}\text { We suggest using either balanced crystalloids or } \\
\text { saline for fluid resuscitation of patients with sepsis } \\
\text { or septic shock }\end{array}$ & $2 \mathrm{C}$ \\
\hline & & $\begin{array}{l}\text { We suggest using albumin in addition to crystalloids } \\
\text { for initial resuscitation and subsequent intravascular } \\
\text { volume replacement in patients with sepsis and septic } \\
\text { shock when patients require substantial amounts of } \\
\text { crystalloids. }\end{array}$ & $2 C$ \\
\hline & & $\begin{array}{l}\text { We recommend against using hydroxyethyl starches } \\
\text { (HESs) for intravascular volume replacement in patients } \\
\text { with sepsis or septic shock }\end{array}$ & $1 \mathrm{~A}$ \\
\hline & & $\begin{array}{l}\text { We suggest using crystalloids over gelatins when } \\
\text { resuscitating patients with sepsis or septic shock }\end{array}$ & $2 C$ \\
\hline $\begin{array}{l}\text { The clinical practice } \\
\text { guideline for the } \\
\text { management of ARDS } \\
\text { in Japan }\end{array}$ & Hashimoto et al. 2017 [64] & $\begin{array}{l}\text { We suggest fluid restriction in the management of } \\
\text { adult patients with ARDS. }\end{array}$ & $\begin{array}{l}\text { 2B } \\
\text { Weak recommendation } \\
\text { Moderate quality } \\
\text { evidence }\end{array}$ \\
\hline $\begin{array}{l}\text { Scandinavian clinical } \\
\text { practice guidelines in } \\
\text { fluid and drug therapy } \\
\text { in adults with acure } \\
\text { respiratory distress } \\
\text { syndrome }\end{array}$ & Claesson et al. 2016 [65] & $\begin{array}{l}\text { We suggest fluid restriction over a liberal fluid strategy } \\
\text { in adults with ARDS }\end{array}$ & $\begin{array}{l}\text { Weak recommendation } \\
\text { Moderate quality } \\
\text { evidence }\end{array}$ \\
\hline \multirow{4}{*}{$\begin{array}{l}\text { European guideline on } \\
\text { management of major } \\
\text { bleeding and coagulopathy } \\
\text { following trauma }\end{array}$} & \multirow[t]{4}{*}{ Rossaint et al., 2016 [88] } & $\begin{array}{l}\text { We recommend that fluid therapy using isotonic } \\
\text { crystalloid solutions be initiated in the hypotensive } \\
\text { bleeding trauma patient }\end{array}$ & $1 \mathrm{~A}$ \\
\hline & & $\begin{array}{l}\text { We suggest that excessive use of } 0.9 \% \mathrm{NaCl} \text { solution } \\
\text { be avoided }\end{array}$ & $2 C$ \\
\hline & & $\begin{array}{l}\text { We recommend that hypotonic solutions such as } \\
\text { Ringer's lactate be avoided in patients with severe } \\
\text { head trauma }\end{array}$ & $1 C$ \\
\hline & & $\begin{array}{l}\text { We suggest the use of colloids be restricted due to } \\
\text { the adverse effects on haemostasis }\end{array}$ & $2 C$ \\
\hline \multirow[t]{4}{*}{$\begin{array}{l}\text { AKI in the perioperative } \\
\text { period \& in ICU: french } \\
\text { expert recommendations }\end{array}$} & \multirow[t]{4}{*}{$\begin{array}{l}\text { Ichai C et al. } \\
2016[111]\end{array}$} & $\begin{array}{l}\text { We recommend not administering hydroxyethylstarch } \\
\text { (HES) in the ICU. } \\
\text { STRONG agreement }\end{array}$ & $1 \mathrm{~B}$ \\
\hline & & $\begin{array}{l}\text { We suggest the preferential use of crystralloid instead } \\
\text { of colloid for fluid loading. } \\
\text { STRONG agreement }\end{array}$ & $2 \mathrm{~A}$ \\
\hline & & $\begin{array}{l}\text { We suggest preferring balanced solutions in case of } \\
\text { large volume loading. } \\
\text { STRONG agreement }\end{array}$ & $2 \mathrm{~A}$ \\
\hline & & $\begin{array}{l}\text { After hemodynamic stabilisation, we suggest avoiding } \\
\text { fluid overload in the ICU. } \\
\text { STRONG agreement }\end{array}$ & $2 \mathrm{~A}$ \\
\hline
\end{tabular}

The table also reports the strenght of recomemantions and GRADE

\section{Albumin}

Albumin is the main determinant of plasma oncotic pressure and has a pivotal role in regulating fluid dynamics at the microvascular level. Albumin also performs other functions that may be relevant for septic patients. These include stabilization of the glycocalyx, transport of molecules, antioxidant effects, immuno-modulation and positive inotropic effects. 
In the SAFE trial, patients admitted to the ICU were randomly assigned to receive albumin or $0.9 \%$ saline for intravascular-fluid resuscitation for 28 days and no difference was observed in all-cause mortality. However, the subgroup analysis of septic patients (planned a-priori) showed an adjusted odds ratio for death of 0.71 (95\% CI: 0.52, 0.97, $p=0.03$ ) for albumin [18].

The ALBIOS trial, which compared administration of albumin (target plasma concentration of $30 \mathrm{~g} / \mathrm{L}$ ) to crystalloids alone showed no difference in outcomes in the study population as a whole and in the subgroups of patients with severe sepsis and septic shock [52]. However, patients with septic shock who were randomised to receive albumin had higher 90-day survival rates $(6.3 \% p=0.04)$ [52].

As noted above, three meta-analyses have recently studied whether human albumin affects mortality when administered for intravascular volume expansion to critically ill patients with sepsis [32-34]. Two of these studies included patients who received crystalloids as well as synthetic colloids in the control arm. The mortality rates were equivalent in the two groups in both of these studies [32, 33]. The third meta-analyses was performed using only crystalloids as the comparator and did not include the data from the EARSS trial which was available only as an abstract [53]. In this meta-analysis, the 90-day mortality of patients in septic shock was significantly lower with albumin [34]. This is concordant with another meta-analysis performed in patients with septic shock [54].

\section{Summary statements:}

- Much of data available regarding the type of fluid to be preferred in patients with sepsis and/or septic shock comes from subgroup or meta-analyses.

- The data suggests that albumin may reduce morbidity and survival in patients with septic shock.

- As a rule, volume substitution septic patients should be undertaken using crystalloids, probably balanced solutions.

- HES must not be used in critically ill patients, septic or not.

- If acute hypovolaemia is not responsive to crystalloids alone, the use of human albumin can be considered.

\section{Adult respiratory distress syndrome}

ARDS was initially considered an inflammatory proteinrich pulmonary edema accompanied by leakage of protein-rich fluids into the interstitial space. The resultant increase in lung weight was thought to generate atelectasis with eventual impairment of lung mechanics and gas exchange $[55,56]$. However, ARDS has both inflammatory edema and hydrostatic components $[55,57,58]$. Development of pulmonary hypertension may lead to an increase in hydrostatic pressure [55]. Activation of the renal aldosterone-angiotensin system during mechanical ventilation also generates high increased intrathoracic pressure which causes water and salt retention $[59,60]$. Fluid loading may improve hemodynamics and oxygenation but it may also worsen lung aeration in patients with lung inflammation through several mechanisms [61]. Moreover, a positive fluid balance in patients with ARDS may increase mortality rate [62].

Data about the best type of fluid in patients with ARDS are scarce. A recent meta-analysis investigated the effect of colloids versus crystalloids in patients with ARDS. Three trials were included for a total of 206 patients. All the included studies compared albumin versus saline. The meta-analysis found improved oxygenation but no survival benefit in patients treated with albumin versus crystalloid [63]. However, the risk of bias of included trials ranged from unclear to high and the sample size was very low.

\section{Summary statements:}

- Fluid management of patients with ARDS has significantly improved over the last two decades but many aspects require clarification.

- Conservative strategies seem to lead to better oxygenation and shorter periods of mechanical ventilation. Although the evidence supporting it is still of moderate quality, conservative fluid administration is recommended in patients with ARDS $[64,65]$.

- The type, timing and dose of fluids to be administered must still be evaluated per-case [53], taking into account the etiology of ARDS (e.g. burns, TBI, infection), patient comorbidities and hemodynamic and respiratory condition [66]

- The type of monitoring used is less important than the composition of the fluids administered and overall fluid balance [67-69].

\section{Major abdominal surgery}

Fluid administration is part of the perioperative routine in both elective and urgent major abdominal surgery but these two situations could not differ more. Elective major abdominal surgery is often accompanied by bowel preparation [70-72], preoperative cardiac assessment when indicated and is performed on a patient that is hemodynamically stable and adequately hydrated. Conversely, patients undergoing urgent abdominal surgery often suffer severe intravascular fluid depletion due to both intestinal and extra-intestinal losses (e.g. vomiting, extra-vascular leakage), are often hemodynamically unstable, and have usually undergone little preoperative assessment.

Elective surgery - The sparse literature addressing perioperative fluid administration in patients undergoing major abdominal surgery refers to elective patients [73]. 
Although mechanical bowel preparation is no longer recommended [74], many patients still undergo drug-induced bowel preparation. Similarly the evidencebased recommendation to allow ingestion of clear fluids up to $2 \mathrm{~h}$ before surgery is often translated to fasting from midnight on the day before surgery [75]. Such practice may induce dehydration and electrolyte imbalance despite institution of corrective hydration.

In this clinical scenario, intraoperative hydration is generally titrated to cover the fluid deficit resulting from bowel preparation and fasting as well as routine fluid maintenance $(2-3 \mathrm{ml} / \mathrm{kg} / \mathrm{h})$. With adequate preoperative preparation however, the fluid deficit in these patients rarely exceeds $2.5 \%$ of body weight. Yet, traditional rehydration during surgery has been shown to result in administration of $7 \mathrm{l}$ of fluid on the day of surgery and a weight gain of 3-6 kg [76-78]. Such practice has led to the current speculation regarding the impact of perioperative fluid administration (both volume and type) on patient physiology.

One ongoing treatment dilemma is whether adding vasopressor therapy to fluid administration is beneficial since such practice may decrease the amount of fluid administered. An early meta-analysis of intra-operative hemodynamic optimization achieved by combining fluids and vasopressors compared to fluids alone showed a decrease in both renal and gastrointestinal complications, but later multicentre trials have yielded mainly controversial results [79-81]. Most of these studies follow patients either throughout admission or to 28 days after surgery. However, none present any data regarding post-operative fluid management, which may have determined the outcomes sought during this time frame.

Regarding the choice of fluids, most discussion still surrounds the issue of crystalloids versus colloids [82]. While newer data does not suffice as yet to support the use of colloids, neither does it suggest that risk is increased. Conversely, there is some evidence that gastro-intestinal outcomes may even be slightly better with colloids [83]. This finding is supported by animal studies suggesting that goal-directed colloid fluid therapy increases microcirculatory blood flow and tissue oxygen tension in healthy and injured peri-anastomotic colon compared to goal-directed or restricted crystalloid fluid therapy [84]. With regards to a direct comparison between balanced crystalloid solutions versus normal saline, even less literature exists. An RCT comparing these solutions in major abdominal surgery demonstrated that balanced solutions caused less electrolyte disturbances, acid-base disequilibrium and increases in NGAL levels and were associated with a stronger anti-inflammatory effect [85].

Urgent surgery - Patients undergoing urgent abdominal surgery often present with sepsis or septic shock.
Therefore, the principles guiding fluid administration in sepsis should also guide perioperative fluid administration. An average patient with a hollow viscus perforation who presents to the department of emergency medicine is likely to receive at least 1-2l of crystalloids before surgery and several litres more during induction of anaesthesia and throughout surgery. These should not be discounted when initiating fluid therapy in the ICU after surgery. The choice of fluids to be administered should be determined by timely information regarding acid-base and electrolyte balance with particular emphasis on avoidance of an unnecessary chloride load. In the setting of severe extravascular leakage, intravascular fluid repletion with crystalloids alone may decrease tissue capillary density, thereby worsening microcirculatory flow dynamics and oxygen delivery. An overload of crystalloid solution may decrease oncotic pressure and viscosity and exacerbate the inflammatory response [86]. Hence the importance of considering the type of fluid in further resuscitation.

\section{Summary statements:}

- Adequate preoperative preparation for elective major abdominal surgery should not induce a fluid deficit exceeding $2.5 \%$ of body weight.

- Most studies regarding fluid administration in the perioperative setting are limited to early therapy.

- Intraoperative/postoperative rehydration of elective cases should be performed with a balanced salt solution. Although this may be accompanied by an increase in circulating cytokines no clinically deleterious effect has been observed.

- Colloids may be administered in elective surgery cases if required- there is no evidence of increased risk in this patient population and there is evidence of better gastrointestinal microcirculatory blood flow and tissue oxygen tension.

- Adding vasopressor therapy to fluid administration remains controversial - while it likely decreases the amount of fluid administered it may also decrease end organ perfusion.

- The principles guiding fluid administration in sepsis should also guide perioperative fluid administration in patients undergoing urgent abdominal surgery.

- The crystalloid chosen for patients after urgent abdominal surgery should be determined individually, based on patient condition at the time of ICU arrival.

\section{Trauma}

Recent years have seen some interesting changes in fluid management of trauma patients. Although severe bleeding is the lead cause of death in trauma patients [87], the European guidelines for management of major bleeding and coagulopathy following trauma strongly 
recommend restricting volume replacement during initial trauma resuscitation [88]. This recommendation is based on data showing not only the feasibility of this approach but also its advantages in term of both process (e.g. hospital length of stay) and outcomes (e.g. survival) [89, 90].

For many years treatment with colloids was considered particularly efficacious in trauma patients. This concept was based on the assumption that the vascular endothelium remains intact after trauma (contrary to septic shock) [91]. Early experimental data supported this assumption, showing that resuscitation with HES 130/0.4 was superior to lactated Ringer [92]. In humans, an exploratory study of patients monitored with a pulmonary artery catheter showed similar hemodynamic outcomes with a lower volume of colloids than crystalloids [93]. However, subgroup analyses of trauma patients included in the RCTs comparing colloids and crystalloids have since failed to confirm this assumption with regards to wither mortality [48] or transfusion requirements [94]. In patients with TBI, mortality was actually higher with albumin than with saline, probably due to the greater increase in intracranial pressure observed during administration of albumin [95]. The European guidelines for management of major bleeding and coagulopathy following trauma therefore recommend isotonic crystalloids rather than colloids for initial resuscitation of hypotensive bleeding trauma patients [88].

Among crystalloid solutions, the respective roles of balanced solutions and saline remain controversial. Unsurprisingly, administration of lactated Ringer solution increases plasma lactate concentrations, whereas normal saline increases the base deficit [96]. In patients with severe TBI, hypotonic solutions (including lactated Ringer) should be avoided as they exacerbate cerebral edema. Conversely, balanced solutions cause less hyperchloremic acidosis than saline in these patients [97]. A RCT of adult trauma patients requiring blood transfusion, intubation, or operation within $60 \mathrm{~min}$ of arrival showed that pre-hospital resuscitation with Plasma-Lyte A yielded better acid-base status and less hyperchloremia 24-h after injury compared with saline [98]. To summarise the use of balanced solutions seems promising for trauma resuscitation but currently remains under investigation [99].

There is ongoing debate regarding intravascular volume expansion with hypertonic saline in trauma patients [100, 101]. Han et al. randomized 294 patients with hypovolemic shock after trauma to receive 3\% hypertonic saline $(n=82), 7.5 \%$ hypertonic saline $(n=80)$, or lactated Ringer $(n=84)$ [102]. Although baseline population characteristics were similar in the three groups, patients receiving hypertonic solutions (3\% or $7.5 \%)$ were given about half the amount of fluids than those given lactated Ringer within the first hour, a difference which disappeared within $24 \mathrm{~h}$. Some side effects (e.g. arrhythmia, hypernatremia) were more commonly observed in patients receiving $7.5 \%$ hypertonic saline, whereas others (e.g. renal failure, coagulopathy, pulmonary edema) were more prevalent among patients receiving lactated Ringer. The authors concluded that among the solutions examined 3\% hypertonic saline has the best safety and efficacy profile [102]. With regards to colloids - the relative contribution of micro-circulatory abnormalities, endothelial dysfunction, local and systemic inflammatory processes and oxidative stress differs between hemorrhagic and septic shock. Decreased tissue perfusion is a major component of haemorrhagic shock whereas inflammatory processes are likely more predominant in septic shock. Hence the effects of HES may also differ. Evidence supporting the presence of a difference includes three meta-analysis showing that the use of HES was not associated with renal effects or clinically significant coagulopathy in the OR [27, 28, 103]. Similarly, no study found deleterious effects of HES in early resuscitation of trauma patients [104]. The European Medicine Agency decided that HES can still be used in surgical patients, and for management of hemorrhagic shock following an initial fluid challenge with crystalloids that has failed. However the clinician should be aware that colloids have not been associated with an improvement in survival in patients with trauma, burns or following surgery [31].

\section{Summary statements:}

- In the hypotensive trauma patient, crystalloids should be administered initially and the amount of fluids administered should be restricted.

- Colloids and hypertonic solutions may accelerate achievement of hemodynamic goals, but have been associated with clinically important side effects and have not been shown to decrease mortality.

Therefore these solutions should not be used as first line therapy.

- Albumin and hypotonic saline should not be administered to patients with TBI.

- The debate between balanced crystalloids and normal saline in trauma remains open, but balanced crystalloids are preferred for large volume resuscitation.

\section{Acute kidney injury}

Fluid administration is one of the cornerstones of prevention of AKI. As with any other body organ, the goal of fluid therapy in this clinical scenario is restoration of intravascular volume with secondary improvement in kidney perfusion pressures and a resultant improvement in local tissue oxygenation. However, the precise relationship between hypo/hypervolemia and AKI remains 
unclear. Studies differ substantially in case mix, fluid volumes and types and the timing of fluid administration. Regardless of the cause and/or mechanism of AKI, macro-circulation alterations (i.e. changes in renal blood flow) are associated with micro-circulation abnormalities (tissue perfusion), endothelial dysfunction, local and systemic inflammatory processes and oxidative stress [105]. The relative contribution of each of these to the development of AKI differs dependent on the cause of renal injury [105]. Whereas decreased tissue perfusion is a major component of haemorrhagic shock, inflammatory processes may be more predominant in AKI caused by septic shock [105]. Patients with sepsis seem particularly susceptible to the deleterious effects of hypervolemia on kidney function [106]. The importance of microcirculatory changes in this clinical scenario makes the choice of fluids all the more crucial.

\section{Gelatins and albumin}

Few studies have assessed the potential renal toxicity of gelatins [36, 38, 107]. An RCT comparing gelatins and crystalloids for fluid resuscitation in septic patients is currently ongoing (NCT 02715466). The RARE trial compared albumin to cystalloids in ICU patients and failed to demonstrate any increase in the risk of AKI [52].

\section{Summary statements:}

- Administration of HES increases the incidence of AKI and RRT in critically ill patients. The use of HES is therefore no longer approved for these patients, regardless of cause of admission.

- No increase has been observed in the rate of AKI in surgical patients or in patients with haemorrhagic shock treated with HES.

- Administration of HES as a second line fluid solution reduces the overall volume of fluid administered to patients.

- The European Medicines Agency suggests that HES is optional as a second line fluid therapy following crystalloids in surgical patients, provided they are not septic or critically ill. This statement requires validation with additional RCTs.

- The data regarding gelatins or albumin in patients at risk of AKI is too sparse to draw meaningful conclusions.

\section{Balanced versus unbalanced fluids}

The clinical benefit of balanced-fluid resuscitation on renal function remains controversial [14]. A single center trial that compared chloride-liberal (saline, $4 \%$ gelatin, $4 \%$ albumin) to chloride-restrictive (lactated crystalloid, balanced crystalloid, $20 \%$ albumin) fluid administration in a nonselective cohort of 1500 ICU patients reported more renal dysfunction in the chloride-liberal group [13].
However, these findings must be interpreted with caution; the difference observed between the groups may have resulted not only from the dose of chloride administered but also from other potentially beneficial measures implemented only in the study group [13]. The large double-blind, cluster-randomized, double cross-over trial, compared 0.9\% Saline versus Plasma-Lyte 148 for ICU fluid therapy (SPLIT) in 2300 hypovolemic patients [51]. No difference was found in the incidence of AKI, RRT between the 2 groups. However, both study and control groups received less fluids than expected; only $2655 \pm$ 3052 and $2554 \pm 2120 \mathrm{ml}$ of study fluids were administered respectively during the 5-day study period. Moreover in the SPLIT trial, the patients were not severely ill and plasma chloride levels were not measured. A meta-analysis of critically ill and surgical patients showed no difference in the rates of mortality and RRT with balanced solutions when compared to unbalanced solutions [108]. However, meta-analyses on this topic are limited by large heterogeneities in case mix, fluid volumes and duration of exposure, underpowering, imprecision, and more.

In 2018, two large-scale randomized studies comparing balanced crystalloids versus saline were published, one in critically ill, and one in non critically ill patients $[109,110]$. Among the 13,347 non-critically ill patients treated in the emergency department, there was no difference in hospital free days [110]. The trial comparing balanced crystalloids (Ringer's solution or plasma-Lyte) to saline in 15,802 critically ill adults showed that the administration of balanced solutions resulted in lower rates of the composite outcome sought (death from any cause, new renal-replacement therapy, or persistent renal dysfunction) [109].

In practice, the systematic use of balanced solutions is not recommended in patients who are not critically ill yet and require low volume resuscitation. Experimental data and large observational studies support potential deleterious renal effects of unbalanced solutions related to severe hyperchloremia. The above mentioned large randomized trial in critically ill patients concluded that the use of balanced solution resulted in less use of renal replacement therapy, less persistent renal dysfunction, and higher survival [109]. A strategy favouring the use of balanced fluids in severe ICU patients requiring high fluid volume resuscitation is recommended [111, 112].

\section{Summary statements:}

- If a large volume of fluid is likely to be required for resuscitation, especially in septic patients, balanced fluid solutions should be selected as these may reduce the likelihood of AKI.

- Despite controversial data, balanced solutions for fluid resuscitation can be favoured even in with small amount of fluids as they may reduce the 
incidence of persistent renal dysfunction and the use of RRT.

- $\mathrm{NaCl} 0.9 \%$ remains useful for patients with hypochloremic alkalosis

\section{Future directions}

In many patients stabilization of the systemic hemodynamic condition is not immediately accompanied by improvement in microcirculatory parameters. This situation may persist for hours or days, indicating long-lasting tissue ischemia [113]. Ongoing microcirculatory derangement is associated with increased morbidity and mortality, even when global hemodynamics are compensated [114]. Studies incorporating data on the effect of various fluids on the microcirculation are needed [115]. Dark-field microscopy, a new technique for measuring microcirculation, may offer important information regarding the microcirculatory changes occurring during administration of various fluids in specific disease conditions [116].

\section{Conclusions}

Intravenous fluids are drugs and should be prescribed as such. Among the available fluids, crystalloids have the highest benefit/risk ratio and, should generally be prescribed first. For critically ill patients or when large amount of fluids is expected to be infused, balanced solutions should be preferred because of their favourable effects on patient outcomes, including kidney function. The preferred solution for non critically ill patients or low volume resuscitation is less clear. However, given the availability of balanced solutions and their low cost, they could be considered for all patients. The role of albumin remains a matter of debate, but there is indirect evidence that albumin may favourably affect the outcomes of patients with septic shock. The indications and effects of gelatins remain unclear for critically ill patients. The role of dextrans in this patient population should probably remain marginal until more data is forthcoming.

\section{Additional files}

Additional file 1: Output of the systematic search. Description of data: Excel table reporting the output of the systematic search (XLSX 485 kb)

Additional file 2: Most relevant studies on fluids in critically ill patients discussed in the main text. Description of data: Table reporting relevant studies on fluids in critically ill patients retrieved by the systematic search (DOCX $151 \mathrm{~kb})$

\section{Abbreviations}

AKI: Acute kidney injury; ARDS: Acute respiratory distress syndrome; $\mathrm{Cl}$ : Cardiac index; CO: Cardiac output; CVP: Central venous pressure; EGDT: Early-goal directed therapy; GFR: Glomerular filtration rate; HES: Hydroxyethyl-starch; ICU: Intensive Care Unit; MFG: Modified fluid gelatine; NGAL: Neutrophil gelatinase-associated lipocain; PLR: Passive leg raising; RBF: Renal blood flow; RCT: Randomized controlled trial; SBP: Systolic blood pressure; SOFA: Sequential Organ Failure Assessment; SV: Stroke volume; TBI: Traumatic brain injury

\section{Acknowledgments}

We thank Dr. Iris Arad for her invaluable help with the literature search.

Funding

None

Availability of data and materials

All data can be retrieved in the manuscript and its supporting information file

Authors' contributions

$\mathrm{CM}, \mathrm{CG}, \mathrm{AC}, \mathrm{IML}, \mathrm{Cl}, \mathrm{ML}, \mathrm{GM}$, SE contributed equally in conceiving the content of the review and writing the manuscript. All authors read and approved the final version of the manuscript.

Ethics approval and consent to participate

Not applicable

\section{Consent for publication}

Not applicable

\section{Competing interests}

Dr. Leone declares fees for lectures from Octapharma, LFB, Aguettant Pharma. Dr. Marx received honoraria for lecturing and grants from BBRAUN. $\mathrm{He}$ is also the coordinator of the German guidelines on fluids. He is also an Associate Editor for BJA and the principal investigator of the Gelatin in ICU and Sepsis (GENIUS) trial. Dr. Cortegiani is an Associate Editor for BMC Anesthesiology. Dr. Martin, Dr. Einav, Dr. Martin-Loeches Dr. Icai and Dr. Gregoretti declare no conflict of interest.

\section{Publisher's Note}

Springer Nature remains neutral with regard to jurisdictional claims in published maps and institutional affiliations.

\section{Author details}

${ }^{1}$ Department of Anesthesia, Intensive Care and Trauma Center, Nord University Hospital, Aix Marseille University, APHM, Marseille, France. ${ }^{2}$ Department of Surgical, Oncological and Oral Science (Di.Chir.On.S.). Section of Anesthesia, Analgesia, Intensive Care and Emergency. Policlinico Paolo Giaccone. University of Palermo, Via del vespro 129, 90127 Palermo, Italy. ${ }^{3}$ St Jame's hospital and Trinity College Dublin, Dublin, Ireland. ${ }^{4}$ Universidad de Barcelona. CIBER, Barcelona, Spain. ${ }^{5}$ Adult Intensive Care Unit, Université Côte d'Azur, University Medicine of Nice, Nice, France. ${ }^{6}$ Department of Anesthesiology and Critical Care Medicine, Aix Marseille University, Assistance Publique Hopitaux de Marseille, Marseille, France. ${ }^{7}$ Department of Intensive Care Medicine, University Hospital RWTH Aachen, Aachen, Germany. ${ }^{8}$ Surgical Intensive Care Unit, Shaare Zedek Medical Centre, Jerusalem, Israel. ${ }^{9}$ Hebrew University Faculty of Medicine, Jerusalem, Israel.

Received: 30 August 2018 Accepted: 12 December 2018 Published online: 22 December 2018

\section{References}

1. Myburgh JA, Mythen MG. Resuscitation Fluids. N Engl J Med. 2013;369: 1243-51.

2. Rhodes A, Evans LE, Alhazzani W, Levy MM, Antonelli M, Ferrer R, et al. Surviving Sepsis campaign: international guidelines for Management of Sepsis and Septic Shock: 2016. Intensive Care Med. 2017;43:304-77.

3. Schindler AW, Marx G. Evidence-based fluid management in the ICU. Curr Opin Anaesthesiol. 2016:29:158-65.

4. Myburgh JA, Finfer S, Bellomo R, Billot L, Cass A, Gattas D, et al. Hydroxyethyl starch or saline for fluid resuscitation in intensive care. N Engl J Med. 2012:367:1901-11.

5. von Heymann C, Sander M, Spies CD. Protocols, physiology, and trials of hydroxyethyl starch. N Engl J Med. 2012;367:1265-6 authorreply1267.

6. Shin CH, Long DR, McLean D, Grabitz SD, Ladha K, Timm FP, et al. Effects of intraoperative fluid management on postoperative outcomes: a hospital registry study. Ann Surg. 2018;267:1084-92. 
7. Thacker JKM, Mountford WK, Ernst FR, Krukas MR, Mythen MMG Perioperative fluid utilization variability and association with outcomes: considerations for enhanced recovery efforts in sample US surgical populations. Ann Surg. 2016;263:502-10.

8. De Backer D, Donadello K, Taccone FS, Ospina-Tascon G, Salgado D, Vincent J-L. Microcirculatory alterations: potential mechanisms and implications for therapy. Ann Intensive Care. 2011;1:27.

9. Hansen PB, Jensen BL, Skott O. Chloride regulates afferent arteriolar contraction in response to depolarization. Hypertension. 1998;32:1066-70.

10. Wilcox CS. Regulation of renal blood flow by plasma chloride. J Clin Invest. 1983;71:726-35.

11. Karakala N, Raghunathan K, Shaw AD. Intravenous fluids in sepsis: what to use and what to avoid. Curr Opin Crit Care. 2013;19:537-43.

12. Scheingraber $S$, Rehm M, Sehmisch C, Finsterer U. Rapid saline infusion produces hyperchloremic acidosis in patients undergoing gynecologic surgery. Anesthesiology. 1999;90:1265-70.

13. Yunos NM, Bellomo R, Hegarty C, Story D, Ho L, Bailey M. Association between a chloride-liberal vs chloride-restrictive intravenous fluid administration strategy and kidney injury in critically ill adults. JAMA. 2012; 308:1566-72.

14. Yunos NM, Bellomo R, Glassford N, Sutcliffe H, Lam Q, Bailey M. Chlorideliberal vs. chloride-restrictive intravenous fluid administration and acute kidney injury: an extended analysis. Intensive Care Med. 2015;41:257-64.

15. Chowdhury AH, Cox EF, Francis ST, Lobo DN. A randomized, controlled, double-blind crossover study on the effects of $2-L$ infusions of $0.9 \%$ saline and plasma-lyte(R) 148 on renal blood flow velocity and renal cortical tissue perfusion in healthy volunteers. Ann Surg. 2012;256:18-24.

16. Guidet B, Martinet O, Boulain T, Philippart F, Poussel JF, Maizel J, et al. Assessment of hemodynamic efficacy and safety of $6 \%$ hydroxyethylstarch $130 / 0.4$ vs. $0.9 \% \mathrm{NaCl}$ fluid replacement in patients with severe sepsis: the CRYSTMAS study. Crit Care. 2012;16:R94

17. Brunkhorst FM, Engel C, Bloos F, Meier-Hellmann A, Ragaller M, Weiler N, et al. Intensive insulin therapy and pentastarch resuscitation in severe sepsis. $N$ Engl J Med. 2008;358:125-39.

18. Finfer S, Bellomo R, Boyce N, French J, Myburgh J, Norton R. A comparison of albumin and saline for fluid resuscitation in the intensive care unit. $N$ Engl J Med. 2004;350:2247-56.

19. Perner A, Haase N, Guttormsen AB, Tenhunen J, Klemenzson G, Aneman A, et al. Hydroxyethyl starch 130/0.42 versus Ringer's acetate in severe sepsis. N Engl J Med. 2012;367:124-34.

20. Bayer O, Schwarzkopf D, Doenst T, Cook D, Kabisch B, Schelenz C, et al. Perioperative fluid therapy with tetrastarch and gelatin in cardiac surgery--a prospective sequential analysis*. Crit Care Med. 2013;41:2532-42.

21. Kashy BK, Podolyak A, Makarova N, Dalton JE, Sessler DI, Kurz A. Effect of hydroxyethyl starch on postoperative kidney function in patients having noncardiac surgery. Anesthesiology. 2014;121:730-9.

22. Joosten A, Delaporte A, Ickx B, Touihri K, Stany I, Barvais L, et al. Crystalloid versus colloid for intraoperative goal-directed fluid therapy using a closedloop system: a randomized, double-blinded, controlled trial in major abdominal surgery. Anesthesiology. 2018;128:55-66.

23. Zarychanski R, Abou-Setta AM, Turgeon AF, Houston BL, McIntyre L, Marshall $J C$, et al. Association of hydroxyethyl starch administration with mortality and acute kidney injury in critically ill patients requiring volume resuscitation: a systematic review and meta-analysis. JAMA. 2013;309:678-88.

24. Gattas DJ, Dan A, Myburgh J, Billot L, Lo S, Finfer S. Fluid resuscitation with 6\% hydroxyethyl starch (130/0.4 and 130/0.42) in acutely ill patients: systematic review of effects on mortality and treatment with renal replacement therapy. Intensive Care Med. 2013;39:558-68.

25. Serpa Neto A, Veelo DP, Peireira VGM, de Assuncao MSC, Manetta JA, Esposito DC, et al. Fluid resuscitation with hydroxyethyl starches in patients with sepsis is associated with an increased incidence of acute kidney injury and use of renal replacement therapy: a systematic review and metaanalysis of the literature. J Crit Care. 2014;29:185.e1-7.

26. He B, Xu B, Xu X, Li L, Ren R, Chen Z, et al. Hydroxyethyl starch versus other fluids for non-septic patients in the intensive care unit: a meta-analysis of randomized controlled trials. Crit Care. 2015;19:92.

27. Van der Linden $P$, James $M$, Mythen $M$, Weiskopf RB. Safety of modern starches used during surgery. Anesth Analg. 2013;116:35-48.

28. Martin C, Jacob M, Vicaut E, Guidet B, Van Aken H, Kurz A. Effect of waxy maize-derived hydroxyethyl starch 130/0.4 on renal function in surgical patients. Anesthesiology. 2013;118:387-94.
29. Hydroxyethyl-starch solutions for infusion to be suspended - CMDh endorses PRAC recommendation [Internet] (Accessed 25 November 2018). Available from: https://www.ema.europa.eu/news/hydroxyethyl-starchsolutions-infusion-be-suspended-cmdh-endorses-prac-recommendation

30. Wiedermann CJ, Eisendle K. Comparison of hydroxyethyl starch regulatory summaries from the Food and Drug Administration and the European medicines agency. J Pharm Policy Pract. 2017;10:12.

31. Perel P, Roberts I, Ker K. Colloids versus crystalloids for fluid resuscitation in critically ill patients. Cochrane Database Syst Rev. 2013:CD000567.

32. Jiang $L$, Jiang $S$, Zhang M, Zheng Z, Ma Y. Albumin versus other fluids for fluid resuscitation in patients with sepsis: a meta-analysis. PLoS One. 2014;9: e114666.

33. Patel A, Laffan MA, Waheed U, Brett SJ. Randomised trials of human albumin for adults with sepsis: systematic review and meta-analysis with trial sequential analysis of all-cause mortality. BMJ. 2014;349:94561.

34. Xu J-Y, Chen Q-H, Xie J-F, Pan C, Liu S-Q, Huang L-W, et al. Comparison of the effects of albumin and crystalloid on mortality in adult patients with severe sepsis and septic shock: a meta-analysis of randomized clinical trials. Crit Care. 2014;18:702.

35. Bunn F, Trivedi D. Colloid solutions for fluid resuscitation. Cochrane Database Syst Rev. 2012:CD001319.

36. Moeller C, Fleischmann C, Thomas-Rueddel D, Vlasakov V, Rochwerg B, Theurer $\mathrm{P}$, et al. How safe is gelatin? A systematic review and meta-analysis of gelatin-containing plasma expanders vs crystalloids and albumin. J Crit Care. 2016;35:75-83.

37. Barron ME, Wilkes MM, Navickis RJ. A systematic review of the comparative safety of colloids. Arch Surg. 2004;139:552-63.

38. Hartog CS, Vlasakov V, Thomas-Rueddel DO, Rueddel H, Hutagalung R, Reinhart K. Efficacy and safety of gelatin for fluid therapy in hypovolemia: a systematic review and meta-analysis. Crit Care. 2011;15:P46.

39. Bayer O, Reinhart K, Sakr Y, Kabisch B, Kohl M, Riedemann NC, et al. Renal effects of synthetic colloids and crystalloids in patients with severe sepsis: a prospective sequential comparison. Crit Care Med. 2011;39:1335-42.

40. Bayer O, Reinhart K, Kohl M, Kabisch B, Marshall J, Sakr Y, et al. Effects of fluid resuscitation with synthetic colloids or crystalloids alone on shock reversal, fluid balance, and patient outcomes in patients with severe sepsis: a prospective sequential analysis. Crit Care Med. 2012;40:2543-51.

41. Saw MM, Chandler B, Ho KM. Benefits and risks of using gelatin solution as a plasma expander for perioperative and critically ill patients: a metaanalysis. Anaesth Intensive Care. 2012;40:17-32.

42. Lorenz W, Duda D, Dick W, Sitter H, Doenicke A, Black A, et al. Incidence and clinical importance of perioperative histamine release: randomised study of volume loading and antihistamines after induction of anaesthesia. Trial Group Mainz/Marburg. Lancet. 1994;343:933-40.

43. Hahn RG. Adverse effects of crystalloid and colloid fluids. Anaesthesio Intensive Ther. 2017;49:303-8.

44. Rivers E, Nguyen B, Havstad S, Ressler J, Muzzin A, Knoblich B, et al. Early goal-directed therapy in the treatment of severe Sepsis and septic shock. N Engl J Med. 2001;345:1368-77.

45. Peake SL, Delaney A, Bailey M, Bellomo R, Cameron PA, Cooper DJ, et al. Goal-directed resuscitation for patients with early septic shock. N Engl J Med. 2014;371:1496-506

46. Mouncey PR, Osborn TM, Power GS, Harrison DA, Sadique MZ, Grieve RD, et al. Trial of early, goal-directed resuscitation for septic shock. N Engl J Med. 2015:372:1301-11.

47. Yealy DM, Kellum JA, Huang DT, Barnato AE, Weissfeld LA, Pike F, Terndrup T, Wang HE, Hou PC, LoVecchio F, Filbin MR, Shapiro NI, Angus DC. A Randomized Trial of Protocol-Based Care for Early Septic Shock. N Engl J Med. 2014;370:1683-93.

48. Annane D, Siami S, Jaber S, Martin C, Elatrous S, Declere AD, et al. Effects of fluid resuscitation with colloids vs crystalloids on mortality in critically ill patients presenting with hypovolemic shock: the CRISTAL randomized trial. JAMA. 2013;310:1809-17.

49. Mahler SA, Conrad SA, Wang H, Arnold TC. Resuscitation with balanced electrolyte solution prevents hyperchloremic metabolic acidosis in patients with diabetic ketoacidosis. Am J Emerg Med. 2011;29:670-4.

50. Neyra JA, Canepa-Escaro F, Li X, Manllo J, Adams-Huet B, Yee J, et al. Association of Hyperchloremia with Hospital Mortality in critically ill septic patients. Crit Care Med. 2015;43:1938-44.

51. Young P, Bailey M, Beasley R, Henderson S, Mackle D, McArthur C, et al. Effect of a buffered crystalloid solution vs saline on acute kidney injury 
among patients in the intensive care unit: the SPLIT randomized clinical trial. JAMA. 2015;314:1701-10.

52. Caironi P, Tognoni G, Masson S, Fumagalli R, Pesenti A, Romero M, et al. Albumin replacement in patients with severe sepsis or septic shock. N Engl J Med. 2014;370:1412-21.

53. Charpentier J, Mira J. Efficacy and tolerance of hyperoncotic albumin administration in septic shock patients : the EARSS study [abstract]. Intensive Care Med. 2011;37(Supplement 2):S115-438 (Abstract number 0438).

54. Wiedermann CJ, Joannidis M. Albumin replacement in severe sepsis or septic shock. N Engl J Med. 2014;371:83.

55. Gattinoni L, Cressoni M, Brazzi L. Fluids in ARDS: from onset through recovery. Curr Opin Crit Care. 2014;20:373-7.

56. Pugin J, Verghese G, Widmer MC, Matthay MA. The alveolar space is the site of intense inflammatory and profibrotic reactions in the early phase of acute respiratory distress syndrome. Crit Care Med. 1999;27:304-12.

57. Sibbald WJ, Short AK, Warshawski FJ, Cunningham DG, Cheung H. Thermal dye measurements of extravascular lung water in critically ill patients. Intravascular Starling forces and extravascular lung water in the adult respiratory distress syndrome. Chest. 1985;87:585-92.

58. Squara P, Dhainaut JF, Artigas A, Carlet J. Hemodynamic profile in severe ARDS: results of the European collaborative ARDS study. Intensive Care Med. 1998;24:1018-28.

59. Bark H, Le Roith D, Nyska M, Glick SM. Elevations in plasma ADH levels during PEEP ventilation in the dog: mechanisms involved. Am J Phys. 1980; 239:E474-81.

60. Koyner JL, Murray PT. Mechanical ventilation and lung-kidney interactions. Clin J Am Soc Nephrol. 2008;3:562-70.

61. Caltabeloti F, Monsel A, Arbelot C, Brisson H, Lu Q, Gu W-J, et al. Early fluid loading in acute respiratory distress syndrome with septic shock deteriorates lung aeration without impairing arterial oxygenation: a lung ultrasound observational study. Crit Care. 2014;18:R91.

62. Rosenberg AL, Dechert RE, Park PK, Bartlett RH. Review of a large clinical series: association of cumulative fluid balance on outcome in acute lung injury: a retrospective review of the ARDSnet tidal volume study cohort. J Intensive Care Med. 2009;24:35-46.

63. Uhlig C, Silva PL, Deckert S, Schmitt J, de Abreu MG. Albumin versus crystalloid solutions in patients with the acute respiratory distress syndrome: a systematic review and meta-analysis. Crit Care. 2014;18:R10.

64. Hashimoto S, Sanui M, Egi M, Ohshimo S, Shiotsuka J, Seo R, et al. The clinical practice guideline for the management of ARDS in Japan. J Intensive Care. 2017;5:50.

65. Claesson J, Freundlich M, Gunnarsson I, Laake JH, Moller MH, Vandvik PO, et al. Scandinavian clinical practice guideline on fluid and drug therapy in adults with acute respiratory distress syndrome. Acta Anaesthesiol Scand. 2016:60:697-709.

66. Vieillard-Baron A, Matthay M, Teboul JL, Bein T, Schultz M, Magder S, et al. Experts' opinion on management of hemodynamics in ARDS patients: focus on the effects of mechanical ventilation. Intensive Care Med. 2016;42:739-49.

67. Monnet X, Bleibtreu A, Ferre A, Dres M, Gharbi R, Richard C, et al. Passive leg-raising and end-expiratory occlusion tests perform better than pulse pressure variation in patients with low respiratory system compliance. Crit Care Med. 2012;40:152-7.

68. Zhang Z, Ni H, Qian Z. Effectiveness of treatment based on PiCCO parameters in critically ill patients with septic shock and/or acute respiratory distress syndrome: a randomized controlled trial. Intensive Care Med. 2015; 41:444-51.

69. Wheeler AP, Bernard GR, Thompson BT, Schoenfeld D, Wiedemann HP, de Boisblanc $B$, et al. Pulmonary-artery versus central venous catheter to guide treatment of acute lung injury. N Engl J Med. 2006;354:2213-24.

70. Sanders G, Arthur C, Hosie KB, Lambert AW. Is patient outcome affected by the Administration of Intravenous Fluid during Bowel Preparation for colonic surgery? Ann R Coll Surg Engl. 2007;89:487-9.

71. Sanders G, Mercer SJ, Saeb-Parsey K, Akhavani MA, Hosie KB, Lambert AW. Randomized clinical trial of intravenous fluid replacement during bowel preparation for surgery. Br J Surg. 2001;88:1363-5.

72. Hahn RG, Bahlmann H, Nilsson L. Dehydration and fluid volume kinetics before major open abdominal surgery. Acta Anaesthesiol Scand. 2014;58: 1258-66.

73. Nisanevich V, Felsenstein I, Almogy G, Weissman C, Einav S, Matot I. Effect of intraoperative fluid management on outcome after intraabdominal surgery. Anesthesiology. 2005;103:25-32.
74. Gustafsson UO, Scott MJ, Schwenk W, Demartines N, Roulin D, Francis N, et al. Guidelines for perioperative care in elective colonic surgery: enhanced recovery after surgery (ERAS(R)) society recommendations. Clin Nutr. 2012; 31:783-800.

75. Brady M, Kinn S, Stuart P. Preoperative fasting for adults to prevent perioperative complications. Cochrane Database Syst Rev. 2003:CD004423.

76. Tambyraja AL, Sengupta F, MacGregor AB, Bartolo DCC, Fearon KCH. Patterns and clinical outcomes associated with routine intravenous sodium and fluid administration after colorectal resection. World J Surg. 2004;28: 1046-51 discussion1051-2

77. Lobo DN, Bostock KA, Neal KR, Perkins AC, Rowlands BJ, Allison SP. Effect of salt and water balance on recovery of gastrointestinal function after elective colonic resection: a randomised controlled trial. Lancet. 2002;359:1812-8.

78. Myles PS, Bellomo R, Corcoran T, Forbes A, Peyton P, Story D, et al. Restrictive versus Liberal fluid therapy for major abdominal surgery. N Engl J Med. 2018;378:2263-74.

79. Pestana D, Espinosa E, Eden A, Najera D, Collar L, Aldecoa C, et al. Perioperative goal-directed hemodynamic optimization using noninvasive cardiac output monitoring in major abdominal surgery: a prospective, randomized, multicenter, pragmatic trial: POEMAS study (PeriOperative goal-directed thErapy in major abdominal surgery). Anesth Analg. 2014;119:579-87.

80. Salzwedel C, Puig J, Carstens A, Bein B, Molnar Z, Kiss K, et al. Perioperative goal-directed hemodynamic therapy based on radial arterial pulse pressure variation and continuous cardiac index trending reduces postoperative complications after major abdominal surgery: a multi-center, prospective, randomized study. Crit Care. 2013;17:R191.

81. Weinberg L, lanno D, Churilov L, Chao I, Scurrah N, Rachbuch C, et al. Restrictive intraoperative fluid optimisation algorithm improves outcomes in patients undergoing pancreaticoduodenectomy: a prospective multicentre randomized controlled trial. PLoS One. 2017;12:e0183313.

82. Yates DRA, Davies SJ, Milner HE, Wilson RJT. Crystalloid or colloid for goaldirected fluid therapy in colorectal surgery. Br J Anaesth. 2014;112:281-9.

83. Ghodraty MR, Rokhtabnak F, Dehghan HR, Pournajafian A, Baghaee Vaji M, Koleini ZS, et al. Crystalloid versus colloid fluids for reduction of postoperative ileus after abdominal operation under combined general and epidural anesthesia. Surgery. 2017;162:1055-62.

84. Kimberger O, Arnberger M, Brandt S, Plock J, Sigurdsson GH, Kurz A, et al. Goal-directed colloid administration improves the microcirculation of healthy and perianastomotic colon. Anesthesiology. 2009;110:496-504

85. Volta CA, Trentini A, Farabegoli L, Manfrinato MC, Alvisi V, Dallocchio F, et al. Effects of two different strategies of fluid administration on inflammatory mediators, plasma electrolytes and acid/base disorders in patients undergoing major abdominal surgery: a randomized double blind study. J Inflamm. 2013;10:29.

86. Naumann DN, Beaven A, Dretzke J, Hutchings S, Midwinter MJ. Searching for the optimal fluid to restore microcirculatory flow dynamics after Haemorrhagic shock: a systematic review of preclinical studies. Shock. 2016:46:609-22.

87. Teixeira PGR, Inaba K, Hadjizacharia P, Brown C, Salim A, Rhee P, et al. Preventable or potentially preventable mortality at a mature trauma center. J Trauma. 2007:63:1338-46 discussion1346-7.

88. Rossaint R, Bouillon B, Cerny V, Coats TJ, Duranteau J, Fernandez-Mondejar $\mathrm{E}$, et al. The European guideline on management of major bleeding and coagulopathy following trauma: fourth edition. Crit Care. 2016:20:100.

89. Bickell WH, Wall MJJ, Pepe PE, Martin RR, Ginger VF, Allen MK, et al. Immediate versus delayed fluid resuscitation for hypotensive patients with penetrating torso injuries. N Engl J Med. 1994;331:1105-9.

90. Schreiber MA, Meier EN, Tisherman SA, Kerby JD, Newgard CD, Brasel K, et al. A controlled resuscitation strategy is feasible and safe in hypotensive trauma patients: results of a prospective randomized pilot trial. J Trauma Acute Care Surg. 2015;78:687-95 discussion695-7.

91. Leone M, Boutiere B, Camoin-Jau L, Albanese J, Horschowsky N, Mege J-L, et al. Systemic endothelial activation is greater in septic than in traumatichemorrhagic shock but does not correlate with endothelial activation in skin biopsies. Crit Care Med. 2002;30:808-14.

92. Ferreira ELA, Terzi RGG, Silva WA, de Moraes AC. Early colloid replacement therapy in a near-fatal model of hemorrhagic shock. Anesth Analg. 2005; 101:1785-91.

93. Heming N, Elatrous $S$, Jaber $S$, Dumenil AS, Cousson J, Forceville $X$, et al. Haemodynamic response to crystalloids or colloids in shock: an exploratory subgroup analysis of a randomised controlled trial. BMJ Open. 2017;7: e016736. 
94. Busuito CM, Ledgerwood AM, Lucas CE. Colloid with high fresh frozen plasma/red blood cell resuscitation does not reduce postoperative fluid needs. J Trauma Acute Care Surg. 2014;76:1008-12.

95. Cooper DJ, Myburgh J, Heritier S, Finfer S, Bellomo R, Billot L, et al. Albumin resuscitation for traumatic brain injury: is intracranial hypertension the cause of increased mortality? J Neurotrauma. 2013;30:512-8.

96. Ross SW, Christmas AB, Fischer PE, Holway H, Walters AL, Seymour R, et al. Impact of common crystalloid solutions on resuscitation markers following class I hemorrhage: a randomized control trial. J Trauma Acute Care Surg. 2015;79:732-40.

97. Roquilly A, Loutrel O, Cinotti R, Rosenczweig E, Flet L, Mahe PJ, et al. Balanced versus chloride-rich solutions for fluid resuscitation in braininjured patients: a randomised double-blind pilot study. Crit Care. 2013; $17:$ R77.

98. Young JB, Utter GH, Schermer CR, Galante JM, Phan HH, Yang Y, et al. Saline versus plasma-Lyte a in initial resuscitation of trauma patients: a randomized trial. Ann Surg. 2014;259:255-62

99. Hammond NE, Bellomo R, Gallagher M, Gattas D, Glass P, Mackle D, et al. The plasma-Lyte 148 v saline (PLUS) study protocol: a multicentre, randomised controlled trial of the effect of intensive care fluid therapy on mortality. Crit Care Resusc. 2017;19:239-46.

100. Bulger EM, Jurkovich GJ, Nathens AB, Copass MK, Hanson S, Cooper C, et al. Hypertonic resuscitation of hypovolemic shock after blunt trauma: a randomized controlled trial. Arch Surg. 2008;143:139-48 discussion149.

101. Wang J-W, Li J-P, Song Y-L, Tan K, Wang Y, Li T, et al. Hypertonic saline in the traumatic hypovolemic shock: meta-analysis. J Surg Res. 2014;191: 448-54.

102. Han J, Ren H-Q, Zhao Q-B, Wu Y-L, Qiao Z-Y. Comparison of 3 and $7.5 \%$ hypertonic saline in resuscitation after traumatic hypovolemic shock. Shock. 2015:43:244-9.

103. Jacob M, Fellahi J-L, Chappell D, Kurz A. The impact of hydroxyethyl starches in cardiac surgery: a meta-analysis. Crit Care. 2014;18:656.

104. James MFM, Michell WL, Joubert IA, Nicol AJ, Navsaria PH, Gillespie RS. Resuscitation with hydroxyethyl starch improves renal function and lactate clearance in penetrating trauma in a randomized controlled study: the FIRST trial (fluids in resuscitation of severe trauma). Br J Anaesth. 2011;107: 693-702.

105. Bellomo R, Kellum JA, Ronco C, Wald R, Martensson J, Maiden M, et al. Acute kidney injury in sepsis. Intensive Care Med. 2017;43:816-28.

106. Kim IY, Kim JH, Lee DW, Lee SB, Rhee H, Seong EY, et al. Fluid overload and survival in critically ill patients with acute kidney injury receiving continuous renal replacement therapy. Burdmann EA, editor. PLoS One. 2017;12: e0172137.

107. Thomas-Rueddel DO, Vlasakov V, Reinhart $K$, Jaeschke R, Rueddel $H$, Hutagalung $R$, et al. Safety of gelatin for volume resuscitation--a systematic review and meta-analysis. Intensive Care Med. 2012;38:1134-42.

108. Kawano-Dourado L, Zampieri FG, Azevedo LCP, Correa TD, Figueiro M, Semler MW, et al. Low- versus high-chloride content intravenous solutions for critically ill and perioperative adult patients: a systematic review and meta-analysis. Anesth Analg. 2018;126:513-21.

109. Semler MW, Self WH, Wanderer JP, Ehrenfeld JM, Wang L, Byrne DW, et al. Balanced crystalloids versus saline in critically ill adults. N Engl J Med. 2018; 378:829-39.

110. Self WH, Semler MW, Wanderer JP, Wang L, Byrne DW, Collins SP, et al. Balanced crystalloids versus saline in noncritically ill adults. N Engl J Med. 2018;378:819-28

111. Ichai C, Vinsonneau C, Souweine B, Armando F, Canet E, Clec'h C, et al. Acute kidney injury in the perioperative period and in intensive care units (excluding renal replacement therapies). Ann Intensive Care. 2016;6:48.

112. Loflin R, Winters ME. Fluid resuscitation in severe Sepsis. Emerg Med Clin North Am. 2017:35:59-74.

113. Hernandez G, Teboul J-L. Is the macrocirculation really dissociated from the microcirculation in septic shock? Intensive Care Med. 2016:42:1621-4.

114. Kiyatkin ME, Bakker J. Lactate and microcirculation as suitable targets for hemodynamic optimization in resuscitation of circulatory shock. Curr Opin Crit Care. 2017;23:348-54

115. van Genderen ME, Engels N, van der Valk RJP, Lima A, Klijn E, Bakker J, et al. Early peripheral perfusion-guided fluid therapy in patients with septic shock. Am J Respir Crit Care Med. 2015:191:477-80.
116. Naumann DN, Mellis C, Smith IM, Mamuza J, Skene I, Harris T, et al. Safety and feasibility of sublingual microcirculation assessment in the emergency department for civilian and military patients with traumatic haemorrhagic shock: a prospective cohort study. BMJ Open. 2016:6:e014162.

\section{Ready to submit your research? Choose BMC and benefit from:}

- fast, convenient online submission

- thorough peer review by experienced researchers in your field

- rapid publication on acceptance

- support for research data, including large and complex data types

- gold Open Access which fosters wider collaboration and increased citations

- maximum visibility for your research: over $100 \mathrm{M}$ website views per year

At BMC, research is always in progress.

Learn more biomedcentral.com/submissions 